\title{
La violencia tiene nombre femenino: Perra brava de Orfa Alarcón. Una mirada a lo abyecto en su escritura
}

\author{
Bisherú Bernal Medel*
}

Las novelas contemporáneas nos sorprenden a menudo por ser muy distintas de aquello que hemos aprendido a admirar y crean una belleza que, al ser tan distinta de la antigua, resulta mucho más difícil de apreciar. Virginia Woolf, “¿Cómo hay que leer un libro?”

Por su intención mimética, el mundo de la ficción nos conduce al corazón del mundo real de la acción.

Paul Ricoeur, La función narrativa

El novelista es un observador, es quien deja un testimonio humano de los cambios sociales. Luis Humberto Crosthwaite

\section{Resumen:}

La violencia generada por el narcotráfico se ha convertido en una realidad inocultable en México, aspecto que ha sido retomado por numerosas plumas en el país. En este artículo se analiza la novela Perra brava de la joven escritora regiomontana Orfa Alarcón. A partir de indagar aspectos como los personajes, los espacios y las voces, se arma la compleja trama que deriva, entre muchos otros elementos, en un peculiar erotismo

${ }^{*}$ Universidad Nacional Autónoma de México. 
perverso que raya en la abyección, el cual se convierte a su vez en un elemento clave para comprender la situación de violencia que padece nuestro actual contexto mexicano.

Palabras clave:

Orfa Alarcón, literatura y narcotráfico, violencia, erotismo, abyección.

Con propuestas frescas y novedosas, la nueva narrativa sobre el narcotráfico llega a través de una infinidad de autores y autoras que, desde perspectivas propias, da cuenta de la realidad que ha rebasado la situación actual de violencia en México. De entre todas ellas, me interesa mostrar la visión de una escritora que ha llamado particularmente la atención por la forma irreverente en que arma sus historias. Me refiero a Orfa Alarcón (Linares Nuevo León, 1979). Su primera novela es Perra brava (Planeta, 2010), aunque es importante mencionar que ya incursionaba en el mundo de las letras como editora, labor que desempeñó por varios años en diversas casas editoriales como Random House Mondadori, Aguilar y Alfaguara Infantil.

La violencia generada por las diversas formas de criminalidad se ha convertido en una realidad inocultable en nuestro país, situación que no ha pasado desapercibida para numerosas voces narrativas que exploran hoy por hoy esta temática. Esa realidad es mimetizada, como marca el epígrafe de Ricoeur, para ser plasmada con diversas particularidades según la pluma escritural. Perra brava es una versión ficcional de este nuevo mundo gore en el cual se ha convertido México: "la gran tumba de los derechos humanos", como también es conocida nuestra nación en la actualidad.

El propósito de este trabajo es realizar un análisis narratológico que aborde las voces, los espacios y las y los personajes, así como

${ }^{1}$ Frase pronunciada durante el discurso de apertura de la Declaración del PEN Internacional, el 24 de febrero de 2015 en la Casa Lamm, Ciudad de México. 
ahondar en la temática de la violencia a través de recursos como la abyección y el erotismo desbordado.

La novela tiene como argumento central la historia de una mujer joven y hermosa, Fernanda Salas, que se enamora de un también joven y atractivo sicario llamado Julio. En ella, la protagonista narra de forma cruda y muchas veces insólita las anécdotas que vive a su lado. El contexto es la situación de violencia en una ciudad del norte de México: Monterrey, Nuevo León. La vida de Fernanda está marcada por el crimen desde la infancia: su padre asesina a su madre bajo los efectos del alcohol y huye, sin darse cuenta de que el cuerpo de su esposa cae justo encima de Fernanda, quien tiene en ese entonces cinco años y casi muere asfixiada. A partir de ese duro acontecimiento Sofía, su hermana, intenta protegerla, pero cuando conoce a Julio poco puede hacer. La existencia de la protagonista se ve entonces marcada por una serie de vertiginosos acontecimientos ante los cuales apenas alcanza a reaccionar. El personaje principal femenino se sumerge en una nueva vida llena de lujos y extravagancias varias, pero también de violencia, muerte, sumisión y sangre -ella, que no soporta la sangre-.

Julio ejerce una especie de fascinación perversa sobre Fernanda, por lo que pierde la voluntad a su lado y, cuando intenta actuar por cuenta propia, él le hace ver que él es quien manda, tanto en la relación como en todo lo que tenga que ver con su vida. Le impone guardaespaldas que no la dejan sola, autoriza o niega sus salidas con amistades e incluso decide sobre cuándo puede ver a su familia; lo que la convierte cada vez más en una solitaria, ante las prolongadas ausencias de su amante.

Pero la trama es todavía más compleja pues hay momentos en los que Fernanda aprovecha ciertos pliegues por los que logra escapar del control masculino: simula un viaje a Japón y en realidad se esconde en un hotel, ahí se cuestiona sobre su vida antes de compartirla con Julio, que en el fondo añora, aunque también disfrute las ventajas - sobre todo económicas- que él le proporciona. El final de la historia es toda una vuelta de tuerca: la protagonista asesina a un hijo de Julio de apenas dos años, con lo que se evidencia la sórdida realidad que permea a las sociedades que son invadidas 
por un ambiente de violencia, impunidad y corrupción. Javier Munguía, al referirse a esta obra, señala que se trata de "una novela que da cuenta del impacto que en una sociedad tiene el narcotráfico: dinero, ostentación, mucha sangre, alianzas con el poder político y corrupción en distintos niveles, entre otros factores". Al ir un poco más allá, cabe preguntarse si, en términos de Jaime Alejandro Rodríguez, hablamos de una "heroína abyecta" (112), pues el personaje de Fernanda es ambiguo y en ocasiones presenta rasgos extremos que tocan los dos polos, como la compasión o el miedo a perder a su familia, mientras que en otras muestra un carácter explosivo y muy violento.

Perra brava sorprende desde su aparición: el mundo mexicano de las letras ha estado acostumbrado por demasiado tiempo a la predominancia de la figura masculina. Esta obra rompe esquemas dobles porque la autora es mujer y por la temática expuesta: una violencia cruda y abismal que bordea la abyección en casi todas sus páginas.

Pero veamos el hilo narratológico del texto para comprender sus claves. La voz narrativa aparece casi todo el tiempo en primera persona del singular, lo que otorga un carácter íntimo a la historia; es la estrategia discursiva más común cuando se pretende lograr este efecto. Un "yo", Fernanda, se dirige a un "tú", al escucha de lo que está siendo contado, aunque en ciertos apartados este esquema se rompe, como veremos a continuación.

La novela es una especie de memorias de la vida de Fernanda junto a Julio: se advierte que lo narrado ya sucedió. Lo anterior se establece desde el primer capítulo, cuando la voz narrativa elabora una pregunta que puede ser retórica pero de inmediato es respondida: “¿Que si valió la pena la relación? Por breve, por enfermiza, por intensa, por su espalda, por su voz, por su porte, por su piel valió la pena una y mil veces; a pesar de lo malo, a pesar de lo doloroso, a pesar de lo rasgado que me haya quedado el corazón" (Alarcón 17). En este giro de la voz puede señalarse también el tipo de focalización que surge desde la consciencia lectora y que responde a esta llamada particular del texto narrativo: me refiero a la focalización existencial, que es completamente dependiente del conflicto de un 
personaje (Del Prado Biezma 23) ${ }^{2}$. Esta mirada privilegia, como su nombre lo indica, las reflexiones existenciales que acosan a la protagonista, la incertidumbre y angustia que la acompañan y que la llevan a cuestionarse sobre su manera de estar en el mundo.

La voz narrativa describe cinco momentos distintos en los que conoce a Julio, los cuales son descritos a través de una serie de analepsis y están divididos en apartados con números romanos dentro del capítulo uno. El primero es durante la secundaria, cuando lo convierte en su amor platónico. En el segundo ya están en la preparatoria; él se comporta como su mejor amigo y es a quien le cuenta sus penas, conoce sus deseos íntimos e incluso la salva del ridículo que protagoniza en la fiesta de graduación. Después, un tercer momento sucede cuando ella ya cursa la universidad, se describe el acontecimiento exacto: Julio llega a un antro del brazo de una compañera llamada Mara, y Fernanda decide en el acto "bajárselo", quedarse con él. Entonces se acerca y le pide a su conocida (Mara) que los presente. El cuarto episodio sucede durante un viaje de la protagonista a Linares para visitar a su tía. Ella no lo reconoce pues está muy cambiado, ya no es el compañero delgado e inseguro que se comportaba como su confidente incondicional; ahora ha desarrollado un físico por demás atractivo. En la quinta descripción la protagonista camina con una vecina por la calle cuando Julio se acerca en un automóvil y le dirige un piropo obsceno. Cada una de las descripciones marca un encuentro entre la protagonista y Julio en distintos momentos del tiempo de la historia. No se sabe cuánta distancia temporal hay entre cada una de las veces que se reencuentran; pero este recurso narrativo de repetición enfatiza la idea de un sino que los une y los separa.

Pero la confusión va más allá pues, según la secuencia en que aparecen las distintas reseñas de su encuentro, no se sabe si ocurrie-

${ }^{2}$ Este autor explica la forma en que se da "el paso de la gesta pública al gesto privado" en lo que fue la novela de aventuras. En este caso, la trama se circunscribe a una historia privada pero no por eso deja de tener aventuras la "heroína"; la "aventura" se ha interiorizado y reducido a dimensiones más íntimas. 
ron una antes que otra o si son cinco posibilidades de la narración. En el siguiente capítulo la voz brinda una clave, confusa también, cuando afirma:

Puedo tener muchas historias, pero sólo hay un nombre. Todas mis historias son ciertas, pero los nombres se borraron y solamente quedó uno: Julio mi niño de prepa, Julio mamón que me avienta el carro, Julio en la secundaria, Julio al que conocí en un antro, Julio que llega a mi vida un mes antes de mi boda y la arruina. Son mis historias más importantes. No quiero perderlas. Lo que olvidé son los nombres. A partir de Julio no hubo uno más, no hubo ninguno antes. Eso era más que suficiente (Alarcón 22).

El enigma no se resuelve pero hay elementos para pensar que son distintas anécdotas con el protagonista masculino, descripciones de encuentros y desencuentros entre ambos; la personalidad agresiva de Julio permite recrearlo en las escenas que ofrece la voz narrativa. La duración de los 79 capítulos es variable pero casi todos son muy breves, lo que le da un efecto de aceleración notable y de contundencia a la trama.

Otros cambios en la voz narrativa están marcados por el destinatario amoroso de las palabras que le dirige Fernanda. En el capítulo 69 ya no narra para el lector implícito, sino que se dirige a Julio: "Pero tú ya no me muerdes" (179), se lamenta la protagonista, pues él da muestras de debilidad ante ella, quien se enamoró precisamente del hombre violento y posesivo. El tema de la violencia es una constante en esta obra, lo que se aprecia de forma particular en este punto. Fernanda está llena de odio y lo demuestra en cualquier oportunidad. Cuando se entera de la existencia de una amante de Julio, desea causarle el mayor mal, a pesar de que uno de los hombres que trabajan para el protagonista masculino le advierte que ya nada tiene que ver "su hombre" con esa mujer. Aun así, Fernanda piensa:

Primero quise matarla, exprimirle los ojos, patearle el vientre, escupirle la cara, arrastrarla de los cabellos, arrancarle a tiras 
la piel. Aunque matarla sería hacerle mucho favor. Después pensé que hacerle todo eso sería dedicarle más fuerza y tiempo de lo que se merecía.

Estropearle la cara: ya no podría ser exhibida.

Quemarle las puertas y las ventanas: que todos vieran que había sido saqueada (187-88).

Hay en la protagonista un inmenso deseo de destrucción, tanto hacia ella misma como hacia los demás, así se trate de gente que de forma fortuita se cruza en su camino. Además, guarda la intención de mandar asesinar a su padre, fantasea con hacerlo e incluso manda investigar su paradero para, en caso de decidirse, concretar sus deseos parricidas.

Poco más adelante, las voces en la consciencia de la protagonista se superponen. Hay un diálogo con el sicario que trabaja para Julio al que le encargó localizar a su padre; al mismo tiempo, aparece como leit motiv la voz de su interior que pide misericordia para sus seres queridos a la hora de su muerte, desea que esta suceda de forma rápida y casi indolora: "Un solo golpe para Julio". "Un solo golpe para Sofía” (Alarcón 182). Este recurso otorga un dramatismo progresivo hacia el final de la trama.

En cuanto a los personajes, la protagonista abarca casi por completo los espacios ficcionales y Julio le sirve como motivo para lograrlo. Fernanda es un efecto de sentido ${ }^{3}$ pero al tratarse de una obra realista cuesta imaginarla como solo eso. Su representación llega a ser tan vívida que lleva a cabo una transformación paulatina a lo largo del relato. Al inicio, como ya se mencionó, es una mujer sumisa y temerosa, situación que cambia conforme avanza la trama. En el momento intermedio de la historia y ante la violencia desmedida de Julio, Fernanda se evade de la dura situación en que

3 Aquí tengo en mente la definición de Luz Aurora Pimentel: “Un personaje no es otra cosa que un efecto de sentido, que bien puede ser del orden de lo moral o de lo psicológico, pero siempre un efecto de sentido logrado por medio de estrategias discursivas y narrativas" (59). 
vive y se aleja a través de la fantasía y la imaginación; evoca su infancia y añora la protección de su hermana Sofía. Una voz interna le ordena negar la realidad en que se encuentra, a la que entró casi sin percatarse: "Sólo fumarás tabaco para no imaginar carreteras, pistolas ni destazados. Después quemarás las sábanas y la ropa. No preguntarás, no pensarás. Ignorarás el horror" (Alarcón 24). Fernanda es también el símbolo de la parálisis de toda una sociedad ante el pánico que inunda las calles de su ciudad y en el que, ella lo sabe, participa Julio. Ante esto, decide callar para no aceptar el contexto que la rodea. Se ciega, lo niega, intenta olvidar, evadirse, sin enfrentarlo ni enfrentarse.

Posteriormente, la protagonista da señas de iniciar un despertar interno, abre los ojos a esa vida de miseria afectiva y emocional que ya ni siquiera le permite disfrutar los lujos que le brinda Julio. Tiene un sueño en el que se repite con insistencia la frase "Nadie tiene a nadie". Y afirma "Cuando me desperté, pensé que sólo me tendría a mí misma, que debía estudiar y rascarme con mis propias uñas" (85). Se trata de un proceso de despertar pero a la inversa, pues se vuelve consciente de la violencia que se ejerce sobre ella pero no inicia una liberación para lograr su bienestar; sino que esta "consciencia" hace que se encamine hacia el ejercicio propio de una violencia mayor que llega incluso a ser peor que la de los matones de los que está rodeada. Así, Fernanda fracasa en su intento de conocerse a sí misma, con lo que inicia su decadencia hacia la abyección personal, que a su vez deriva en la social.

Julio recorre un camino inverso: su nivel de violencia se reduce debido a que conforme avanza la trama, se enamora cada vez más de Fernanda, lo que se traduce en la pérdida de su característico autoritarismo machista. Los "Cabrones", grupo de matones a su servicio, se dan cuenta de eso; reduciendo aún más el respeto y miedo que le tenían. El final es ilustrativo con relación a la transformación del personaje masculino antagónico, pues prefiere suicidarse que asesinar a la protagonista; reconociéndose incapaz de vengar la muerte de su pequeño hijo de dos años a costa de lastimarla.

Los demás personajes son accesorios y no influyen de manera determinante en la trama; a excepción de "El Chino", uno de los 
"Cabrones" que rompe el estereotipo de lo que es un matón, pues lee a Bajtín y estudió Lingüística, además de que no se emborracha ni se droga. Él también se enamora de Fernanda, quien lo intenta manipular sin lograrlo cuando descubre el poder que ejerce sobre él.

Los espacios ${ }^{4}$ de la historia tienen un espejo nítido en la realidad extratextual y tanto las ciudades (Monterrey, lugar donde se desarrolla mayoritariamente la trama; Linares y la zona de San Pedro Garza) como marcas comerciales (Louis Vuitton, Versace, Tous, BMW, entre otras) aparecen de manera profusa en la obra. También se citan muchas calles y zonas típicas de la ciudad regia.

A pesar de que ciertas nociones de la teoría literaria tradicional llegan a tener una rigidez que es difícil romper, se puede afirmar que esta novela cohabita temáticamente con la realidad externa del relato $^{5}$. En este sentido, propuestas como la de la crítica argentina Josefina Ludmer arrojan luz sobre las nuevas formas en que analizamos los textos, con mayor razón si estas escrituras son de reciente producción. En su artículo "Literaturas posautónomas", la especialista plantea la necesidad de renovar la forma en que nos acercamos a la literatura en América Latina. Define lo posautónomo como la literatura generada en esta gran región del continente después de los años 60 del siglo pasado, representada desde el canon por el llamado boom latinoamericano. Así, Ludmer habla de la necesaria libertad al analizar las obras latinoamericanas para realizar una ruptura, que no es tajante, con la crítica literaria clásica. Y afirma: "La posautonomía no cierra el ciclo que se abrió en el siglo

${ }^{4}$ Cuando hablamos del espacio en el relato nos referimos a la "ilusión del espacio" que se produce en quien está leyendo, gracias a una serie de recursos descriptivos altamente codificados (Pimentel 26-7).

${ }^{5}$ Pimentel ofrece una definición pertinente del mismo. El relato sería entonces "Una construcción progresiva, por la mediación de un narrador, de un mundo de acción e interacción humanas, cuyo referente puede ser real o ficcional" (10). Se observa que hay mayor flexibilidad en este concepto, pues por lo general en la novela la literatura clásica condiciona el rasgo ficcional a su carácter intrínseco. 
XVIII, cuando cada esfera (lo político, lo literario, lo económico) se define en su especificidad (y autorreferencia); pero lo altera y lo pone en cuestión" (Ludmer) ${ }^{6}$. Esta idea permite que la literatura sea un campo más abierto hacia otros, además de que también difumina las barreras totales entre los mismos géneros literarios.

Pero la propuesta quizá más interesante que aporta esta pensadora en el artículo citado, se refiere a un nuevo término que acuña: la "realidadficción"; así, las palabras unidas formando sólo una:

La materia de la literatura es la misma de la imaginación pública (o fábrica de realidad): la realidad ficción. En muchas escrituras se borra la separación entre realidad y ficción: no se sabe si lo que se cuenta ocurrió o no, si los personajes son reales o no. Esta borradura forma parte del proceso general que afecta a las oposiciones binarias [...]. En el caso de la realidad y la ficción puede verse cómo funciona ese proceso de desdiferenciación de las oposiciones: un polo "se come" a otro y se reformula. Y este es el caso de la ficción hoy, que habría cambiado de estatuto porque ya no parece constituir un género o un fenómeno específico sino abarcar la realidad hasta confundirse con ella [...]. El resultado es una mezcla indiscernible, una fusión: la realidadficción (Ludmer).

Perra brava tiene elementos que sin duda se acercan a la definición descrita. Y en ese sentido llama la atención la insistencia de Orfa Alarcón al aclarar que se trata de una obra de carácter ficcional, pues en la hoja de datos aparece una especie de advertencia que señala que, a pesar de que la trama hace referencia a personajes y acontecimientos reales, estos solo dan autenticidad al mundo de la imaginación que creó la autora. En la portada se imprime con letras pequeñas la palabra "Novela", y al final se vuelve a afirmar que se

${ }^{6}$ Cabe señalar que en este artículo la autora utiliza los dos términos: "postautónomas" y "posautónomas"; unifico utilizando el segundo por considerar que la forma simplificada es la mejor opción. 
trata de "una historia de ficción". Dos cosas me interesa señalar sobre esto. La primera es que una vez que el autor o autora escribe un texto y lo publica, deja de ser solamente suyo; este vuela y se convierte en, como dice Ludmer, un producto de la imaginación pública. Lo segundo se refiere a que, si bien la autora tiene todo el derecho a defender el carácter ficcional de su libro, también reconoce que se nutrió de la nota roja para escribirlo. Irene Torres López, quien la entrevistó para un medio virtual, afirma que "La trama fue cosechada por Orfa gracias al bombardeo de notas rojas que diariamente aparecen en los medios de comunicación; ella, como muchos autores, ha publicado un libro en donde el narco se inmiscuyó como una idea, un personaje o una crónica". Aunque Alarcón defiende la creación de la protagonista como suya y de nadie más, acepta que algunos detalles sí están basados en notas periodísticas. Así, podemos concluir que la autora genera un vaivén entre ficción y realidad que lleva a las y los lectores a cuestionarse el principio de verdad dentro de la novela.

El lenguaje es claro, directo y común, además de muy violento; aspectos en los que se aleja del canon literario. Acerca de esto, Alarcón habla de la importancia que la oralidad tiene en su novela:

La literatura tiene que sostenerse en el lenguaje, una novela que le tenga miedo a la expresión natural del pueblo no funciona. A mí me gusta mucho trabajar con oralidades, es un fenómeno que vengo estudiando desde hace años y lo único que hice fue dejar que los personajes hablaran con toda la crudeza que hablan las personas que viven en el norte del país (Aguilar).

En las palabras de la narradora se advierte otro rasgo de la realidadficción: la utilización de un lenguaje que extrae de la realidad externa al texto, en este caso propia de las y los hablantes norteños.

Luzelena Gutiérrez de Velasco resalta el carácter poético que también tiene la novela; pues aparece en ella lo que la crítica citada llama: 
[...] la dureza del lenguaje, entreverada con un lenguaje que se instaura como un registro poético"7. La interrelación de los personajes está llena de insultos, de malas palabras, lo que representa el nivel cultural que poseen tanto estudiantes como sicarios. A veces ese lenguaje encubre un afecto que no puede mostrarse en un ámbito de fuerza o dureza (108).

Es la anterior una clave para comprender la compleja dinámica del texto, pues los personajes, todos, son incapaces de expresar sus sentimientos, mucho menos las emociones que los embargan, lo que se convierte en una dificultad que les impide abrirse y comunicarse entre ellos. Como afirma Élmer Mendoza: "Los personajes son estatuas que llevan la belleza y el mensaje en sí mismos, además de un contraste espectacular. Orfa Alarcón los ha plantado frente a un mundo que no podrá escabullirse de sí mismo, que deberá dejar de esperar que las nuevas generaciones salven lo que han echado a perder" (2).

Perra brava da cuenta de ciertos recursos discursivos como el hiperrealismo, el grotesco y el humor, aunque del último encontramos muy poco. Hay partes de la novela que parecen calcados de la realidad extratextual, como cuando Fernanda casi se pasa un semáforo en rojo y frena, entonces una señora de otro auto le hace señas por su imprudencia; acto que le molesta y resulta suficiente para que decida "vengarse". La persigue y le enseña un arma: "Alcé la pistola con la izquierda nada más para que la tipa la viera. En cuanto volteó, gritó, perdió el control y se subió a la banqueta" (Alarcón 108) estrellándose contra un árbol. Este pequeño episodio sirve para mostrar, como ya se mencionó, la profunda violencia que alberga en su interior la protagonista; ya que por un incidente de tránsito insignificante ella causa un accidente, a pesar de que quien comete la falta es ella. Es por demás conocido que en numerosas ciudades del norte mexicano este tipo de situaciones son cotidianas,

${ }^{7} \mathrm{Y}$ sobre este aspecto es indispensable mencionar Rayuela de Julio Cortázar, novela con la que mantiene un diálogo de intertextualidad importante. 
al grado de que la población está ya acostumbrada a permitir múltiples abusos cuando sospecha que quien los lleva a cabo es miembro del llamado crimen organizado. Se puede observar que actos como el descrito exhiben la prepotencia criminal; estos se retoman en la trama pero tienen un paralelismo fiel con la vida real. Son hiperreales en el sentido de que amplifican ciertos ángulos y rasgos de la vida cotidiana en muchas regiones de México.

En cuanto al humor, es importante señalar que aparece poco pero siempre en momentos en los que la protagonista está relajada, cuando se sumerge en su vida universitaria, platicando con su mejor amigo, Dante. En una ocasión está a punto de perder el semestre debido a la poca dedicación que le prestó a sus estudios por haberse mudado con Julio, entonces y después de una relativa ausencia, regresa a la universidad y de inmediato le confiesa a Dante: "Vine a recuperar el semestre, me acueste con quien me acueste" (Alarcón 89). En otros momentos, también acompañada de su mejor amigo, ambos muestran cierta alegría que se traduce en chistes y que se ve opacada en cuanto aparece en la historia cualquier vestigio de su vida como pareja de un sicario. Cuando vive una "vida de una chava normal" es cuando aflora el humor, nunca en su contexto cotidiano, tan cercano a la violencia criminal de Julio y los "Cabrones".

Dante es un personaje peculiar que le da colorido a la trama, su ánimo abierto y alegre le transmite humor al carácter sobrio de Fernanda. Aparentemente es un joven gay frívolo, pero conforme avanza la historia muestra cada vez mayor calidad humana que la misma protagonista quien, como ya se ha mencionado, se degrada de forma progresiva. Dante, en contraste, aumenta su consciencia y reacciona con horror y rechazo ante la violencia desmedida con la que actúa Fernanda, por lo que decide romper la amistad y evitar convertirse en su cómplice. 


\section{La corporalidad abyecta en Perra brava}

En la discursividad traumática de lo abyecto, el cuerpo, en su literalidad, tiene la última palabra. Fabián Giménez Gatto, Erótica de la banalidad.

Andabas por la noche como quien no teme al despojo, a la tortura, a las desapariciones, al frío del metal sobre los ojos, al ruido de las balas, a ser uno contra doce, a las sospechas, a la policía, a las falsas acusaciones, al rumor de ser de «los otros», al ejército, a la sangre que chorrea de las cajuelas de otros vehículos, a la envidia hacia tu camioneta negra. Andabas por la noche como quien busca la muerte. Orfa Alarcón, "Lobo".

La corporalidad en Perra brava se asocia de manera indiscernible con la abyección, como marca el epígrafe de Giménez Gatto. El tema central que me interesa explorar en esta parte del análisis se encuentra también muy relacionado con la violencia; me refiero a lo abyecto en la obra. La escena inicial de la novela será el episodio elegido debido a que es una de las más impactantes por su cruda descripción. Al inicio de la historia, Julio irrumpe de forma sigilosa en la casa que comparten, sorprende a Fernanda y la inmoviliza:

Supe que con una mano podría matarme. Me había sujetado del cuello, su cuerpo me oprimía en la oscuridad. Había atravesado la casa sin encender ninguna luz ni hacer un solo ruido. No me asustó porque siempre llegaba sin avisar: dueño y señor. Puso su mano sobre mi boca y dijo algo que no alcancé a entender. No pude preguntar. Él comenzó a morderme los senos y me sujetó ambos brazos, como si yo fuera a resistirme (cursivas mías) (Alarcón 11).

Se recrea en la escena una especie de violación, juego consensuado por momentos pero que en otros se convierte en una especie de pesadilla para ella: "me penetraba como enfurecido, como él, 
como demostrando quién era. Y el dolor le ganaba lugar al placer, y yo sólo quería que me dejara respirar, que terminara antes de que me rompiera algún bueso" (12). (Cursivas mías)

Se trata de un juego violento y placentero que disfrutan ambos componentes de la pareja. Pero se observa también que por momentos a ella no le gusta el juego, desea que termine pero no se atreve a expresarlo. En la novela, una de las modalidades de violencia que aparece con más fuerza es precisamente la que se da entre los protagonistas, la de pareja; que como veremos a detalle se irá transformando hasta volverse insólita. En la siguiente cita, se advierte de forma nítida que este tipo de encuentros sexuales entre Fernanda y Julio suceden con cierta frecuencia:

Nunca me opuse a esta clase de juegos. Me excitan las situaciones de poder en las que hay un sometido y un agresor. Me excitaba todavía más entender que para él no eran simplemente juegos sexuales: Julio doblegaba mi mente, mi cuerpo, mi voluntad absoluta. De noche y de día, acompañados o solos, dormidos o despiertos (Alarcón 11).

¿Cómo entender este tipo de juegos eróticos? ¿Qué es lo que generan al relacionarse de forma agresiva, además de la evidente carga de adrenalina? La violencia sin duda es clave en la búsqueda de respuestas. Hay un acuerdo tácito que permite precisamente lo que ha descrito la voz narrativa; un juego de poder donde quien domina es Julio y quien se somete es Fernanda. Esto sucede al inicio de la historia; ella se encuentra completamente rendida ante él. Aunque después los papeles se invertirán.

Giménez Gatto, en su ensayo titulado Erótica de la banalidad, describe la noción de cuerpos explícitos, aquellos que representan: "La abyección como programa, es decir, como conexión de deseos, conjunción de flujos y continnum de intensidades, problematiza la corporalidad en una deriva más allá del organismo, la significancia y la subjetivación” (Giménez Gatto, 2011: 75).

La noción otorgada por este teórico nos remite a relaciones que exceden la llamada norma; nos confrontan con lo abyecto, con 
lo que se desborda. Este concepto se aproxima a la forma en que la pareja protagonista vive sus cuerpos; Fernanda asume su papel de dominada pero no le interesa la pasividad total; participa, muerde, rasguña, lastima al ser amado hasta llevarlo al símbolo por excelencia de la abyección: la muerte; aunque eso ocurrirá hacia el final del relato.

Al seguir el hilo del análisis, la violencia en la escena elegida va más allá, porque Julio decide darle una 'lección’ a Fernanda para que despierte del letargo infantilizado y cómodo en que ha permanecido gran parte de su vida, lecho cálido -hasta cierto punto- que la ha cobijado gracias sobre todo a su hermana, quien la ha sobreprotegido.

Además de la escena sexual de sometimiento descrita con anterioridad, también la condena a una violencia mayor: Julio se ha embarrado la sangre de un hombre que asesinó y en una suerte de ritual abyecto obliga a Fernanda a que recorra su cuerpo con la lengua. La oscuridad le impide ver lo que sucede. Recordemos que ella no soporta la visión de este fluido corporal. De esta forma le hace saber que no permitirá "delicadezas", como su aversión enfermiza hacia la sangre. El desenlace de esta fuerte escena impacta por su total crudeza:

Por primera vez su sabor no me gustaba, era extraño, nuevo, agrio. Nauseabundo. [...] Julio al fin se vino y se quedó dormido. Me abracé contra él. También me hubiera gustado quedarme dormida, de no ser por ese sabor molesto que aún sentía en la lengua. Amodorrada me levanté a orinar y a lavarme los dientes. Entonces entendí las palabras de Julio: al tomar la pasta de dientes me descubrí frente al espejo con la cara llena de sangre. Los senos, las manos, la entrepierna. Grité. Como si viera el fantasma de mi madre. Grité tan fuerte que me quedé ronca. Julio entró al baño y me abofeteó (Alarcón 12).

Y el protagonista masculino corona con estas violentas palabras su acto abyecto, increíble, inconcebible: 
-Para que te lo sepas, traes encima la sangre de un cabrón con muchos huevos, y con todo y todo se lo cargó la chingada, porque la vida se gana a putazos. Así que no me vuelves a salir con que no puedes freír ni un pinche bistec porque te da asco. A mí no me sales con esas pendejaditas (12-13).

Es "la muerte infestando la vida" (Kristeva); la combinación de fluidos corporales: un cuerpo vivo, estético, es recorrido y está cubierto de sangre seca que va siendo humedecida por el fluido vivo de la saliva, hasta culminar en la mezcla total, abyecta, de sangre, semen, sudor y saliva.

Es importante detenernos un momento y destacar la importancia que el erotismo tiene en la obra. Este término, polisémico en ocasiones, ahora se presenta como ese vínculo indisoluble entre el placer y la muerte. La delgada línea que une la pasión con la abyección. Veamos cómo se desarrolla este sentimiento entre los protagonistas.

Una referencia ineludible para observar esta noción es Georges Bataille. En El erotismo, la frase inicial es una afirmación contundente: "Podemos decir del erotismo que es la aprobación de la vida hasta en la muerte" (8). Esa unión indisoluble que hay entre erotismo y muerte, ese deseo de continuidad a través del otro componente de la pareja, ese deseo inequívoco de querer fundirse con el otro (otra) es en sí lo que desborda al ser humano y lo hace cuestionarse sobre "la exuberancia de la vida"; que por supuesto no está alejada de la muerte. Vuelve el teórico francés a reafirmar esta idea: “Toda la operación del erotismo tiene como fin alcanzar al ser en lo más íntimo, hasta el punto del desfallecimiento. El paso del estado normal al estado de deseo erótico supone en nosotros una disolución relativa del ser, tal como está constituido en el orden de la discontinuidad" (12-13). ¿Qué sucede en la novela con el erotismo grotesco, que desborda el sentido cotidiano de lo sensual/sexual? La atracción que sienten los protagonistas bordea la animalidad, tiene un aire primitivo que los lleva a disfrutar el erotismo más allá de los límites conocidos; hasta ese "punto del desfallecimiento", hasta la "disolución del ser" que sumerge por momentos a los protagonistas en esa sensación de continuidad, en la ilusión de compartir un 
real sentimiento que los salva, aunque sea por breves momentos, del entorno cotidiano asfixiante en que se desenvuelven.

Siguiendo con el vínculo entre erotismo y muerte, el significado que guarda el hecho de que Julio se unte sangre cuando sabe que copulará con Fernanda va más allá, sobre todo si tomamos en cuenta que, como afirma Bataille: "Por sí misma, ya la sangre es signo de violencia" (38). El protagonista masculino sí disfruta el hecho de que Fernanda, sin saberlo, vence su propio asco y supera la repugnancia infinita que siente hacia la sangre debido a la excitación que la invade. El deseo y el horror en un vínculo inaprensible:

Para llegar hasta el final del éxtasis donde nos perdemos en el goce, siempre debemos poner un límite inmediato: el horror. No sólo el dolor de los demás o el mío propio al acercarme al momento en que el horror se apoderará de mí puede hacerme alcanzar un estado gozoso que raye en el delirio, sino que no hay forma de repugnancia en la cual no pueda discernir afinidad con el deseo. No es que el horror se confunda alguna vez con la atracción, pero si no puede inhibirla o destruirla, el horror refuerza la atracción. El peligro paraliza, pero al ser menos fuerte puede excitar el deseo. Sólo alcanzamos el éxtasis en la perspectiva, aún lejana, de la muerte, de lo que nos destruye (198).

En la pareja protagonista es precisamente el horror el que los acerca, el erotismo los ayuda a sobrellevar esa cotidianidad de sangre y muerte en la que están inmersos. Y es quizá la escena descrita donde nace la nueva versión de la protagonista: una Fernanda cruel, caprichosa y violenta, que ahora aparece dispuesta a ejercer todo el resentimiento y la furia que tiene dentro y que la irán conduciendo a la abyección, probablemente sin retorno.

En otro sentido, se encuentra además la violencia más sutil pero también importante: la de asumir que Fernanda debe saber "freír un bistec" por el hecho de ser mujer, su mujer. Se trata de un espacio narrativo plagado de violencias múltiples; lo abyecto asoma a cada paso en algunos de los pliegues de la historia que apenas deja espacio para respirar. 
Hay una especie de erotismo perverso entre ambos, pues a él, símbolo del macho promedio, le gusta someter e insultar a la protagonista; situación que ella también disfruta aunque con matices. Además, transgrede los mandatos de su género al exigir un papel activo, quiere participar en el juego de amor violento y poder morderlo, rasguñarlo, lastimarlo.

Fernanda, a través de su cuerpo, vive ese erotismo perverso que raya sin duda en lo abyecto, pero que es disfrutado y no solo gozado por ella. El goce entendido como esa sensación que conecta con la herida, que desacomoda pero que también se vincula con el lado disfrutable, el del placer (cf. Barthes).

A través de la trama los personajes principales se muestran como dos seres infelizmente felices haciéndose daño, viviendo en el goce entendido como "estado de pérdida" (Barthes 25), de eterno vacío; en una búsqueda incesante que les permita la inalcanzable tranquilidad que les daría una vida fuera del entorno violento en que se desenvuelven.

Por su parte, Giménez Gatto vincula la noción de lo abyecto con la deformidad, lo que no encaja, lo que sobra (77). En contraste los protagonistas, desde la perfección de sus cuerpos, tocan lo abyecto casi por elección, quizá también por inercia. Sus cuerpos son anatómicamente correctos, pero hay una pérdida, un vacío interno, "metafísico", diría Gimenez Gatto, que es difícil de llenar y que conduce a los personajes a destruir su entorno y a autodestruirse de diversas formas; a través del suicidio en el caso de Julio; a rebasar los límites éticos y atentar contra la vida de un menor en el caso de Fernanda. Se trata en este punto de evitar un juicio hacia ellos (hacia su representación), pues a pesar de que sin duda asombra el alto grado de abyección al que se degradan, resulta imprescindible recurrir a la realidad extratextual que se hermana con la ficcional (pienso en el concepto de realidadficción de Josefina Ludmer ya mencionado) y preguntarnos como sociedad qué estamos viviendo para que ocurran en el devenir cotidiano este tipo de actos. Recordemos que una de las funciones de la literatura es conducirnos al cuestionamiento sobre nuestra existencia, también social y sobre nuestro lugar en el mundo. 


\section{Reflexiones finales}

Reír es una forma de situar o de desplazar la abyección. Julia Kristeva, Poderes del horror.

En Perra brava se presenta una especie de erotismo perverso, donde los cuerpos se regodean en el goce (Barthes, Kristeva); lo que brinda elementos claves que buscan desentrañar posibles sentidos de la violencia. Kristeva nos dice sobre este tema que: "Lo abyecto está emparentado con la perversión. El sentimiento de abyección que experimento se ancla en el superyó. Lo abyecto es perverso ya que no abandona ni asume una interdicción, una regla o una ley, sino que la desvía, la descamina, la corrompe" (14).

Orfa Alarcón da cuenta de esta dura temática con un directo y peculiar estilo que nos lleva a reflexionar sobre la forma en que la representación de la violencia ligada al placer transgrede la visión convencional patriarcal del sexo en una relación cuya visión de lo "amoroso" resulta particular. La otra cruda temática, la social, es representada en la obra a través de la hiperviolencia que se asemeja a episodios de la realidad extratextual, como el del semáforo y la actitud de prepotencia criminal que personifica la protagonista.

Otro aspecto a resaltar es la transformación a la inversa que se da en la pareja protagonista. Al inicio de la narración Fernanda está consciente de que Julio la domina, lo asume con docilidad. Pero al paso del tiempo, en ella se produce un cambio paulatino y se vuelve cada vez más violenta; mientras que Julio pierde poder y voluntad ante Fernanda; situación de la que se percatan los hombres que trabajan para él y hace que le vayan perdiendo el respeto; pues mostrar debilidad es algo inaceptable en ese entorno masculinizado hasta el extremo. Así, los personajes se transforman a la inversa entre ellos, dando paso a una versión transgresora de ver y vivir la violencia desde perspectivas no convencionales que cuestionan preconcepciones sobre los roles que desempeña cada género frente a la violencia.

El horror y la violencia magnificada unen a los protagonistas, quienes encuentran un espacio para evadirse de sus inefables exis- 
tencias en el sexo violento y también en el erotismo, entendido este último como el límite del placer agónico que deriva en la muerte. El resultado en ambos casos es la caída al abismo de lo abyecto, del vacío interior que no logran romper ni llenar por cauces constructivos; por el contrario, dejan que aflore la furia constante en cada movimiento de sus existencias. El enojo se vuelve protagonista y se manifiesta a través de la violencia. Se trata de la actitud característica que desempeñan, en distintos momentos, los protagonistas en la trama.

Fernanda se convierte en el símbolo de una sociedad paralizada que poco ha hecho ante tanta muerte, tanta desaparición, tanto crimen; una sociedad que no ha alcanzado a reaccionar y a la que seguramente el tiempo cobrará (de alguna forma ya lo está haciendo) este pesado silencio. Asumir esa responsabilidad hará, en todo caso, la diferencia en un futuro que, como ya advertía el movimiento neozapatista en los inicios del siglo XXI, será colectivo o no será.

Fernanda aparece en efecto como una "heroína abyecta", que se degrada progresivamente conforme avanza la trama. Pierde interés en Julio cuando ya no la maltrata y se vuelve más violenta. Ya no parece haber vuelta atrás, aunque el final es abierto y ella huye después de que Julio se suicida para no matarla, con un destino incierto pero con la suficiente sangre fría como para volver a armar un grupo criminal; posible final de la historia. En otra versión, podría dejar la vida delictiva, pero dado el contexto descrito resulta menos probable que la anterior.

En contraparte, el personaje de Dante otorga luz a otro ángulo del desolador panorama mostrado en la novela: él simboliza la parte de la sociedad que no está dispuesta a volverse cómplice del deterioro moral y grotesco que personifica Fernanda y los sicarios de los que se rodea. Dante ofrece una esperanza, aunque pequeña, de la posibilidad de transformación que todavía es posible a través de la reflexión literal (al vernos en el espejo de la abyección social representada) que brindan obras como Perra brava.

La novela devela distintas aristas que invitan al análisis de la tremenda realidad presentada a través de esta ventana que es la literatura, y busca al mismo tiempo explorar las inexplicables reacciones 
que caracterizan al género humano, en este caso plasmadas por la joven escritora regiomontana.

¿Qué nos queda por decir sobre lo abyecto? Apelando de nuevo a la escritura y a la literatura que nos permite reflexionar sobre nuestro presente y nuestro sentido de historia, de memoria proyectada hacia el futuro, quizá lo único y lo más importante es reflexionar sobre la idea de que probablemente la abyección también nos habita; Kristeva nos recuerda aquello que "descartamos permanentemente para vivir" desde nuestros cuerpos, y al final, nosotras/nosotros mismos seremos pura abyección (9). Lo anterior nos lleva a repensar la situación actual en México, al recordar que hemos permitido, así sea por omisión, que nuestro país se suma en el oscuro pozo de lo abyecto; y obras como la aquí analizada invitan a la reflexión que abonará para emerger de la gran noche oscura en que se encuentra nuestra nación.

Amena, ágil, vertiginosa, contundente y con una vigencia asombrosa, Perra brava gana cada vez más adeptos a pesar de que en la actualidad solo está disponible su versión electrónica. Por ahora baste decir que con la temática transgresora que presenta, supera con mucho las expectativas de su género en el mundo literario contemporáneo.

\section{Obras consultadas}

Aguilar, Yanet. “Tres jóvenes escritoras narran la violencia”. El Universal, 8 marzo 2014, http://archivo.eluniversal.com.mx/cultu$\mathrm{ra} / 2014 /$ impreso/tres-jvenes-escritoras-73717.html.

Alarcón, Orfa. Perra brava. Planeta, 2010.

Bataille, Georges. El erotismo. Biblioteca Virtual Dip. Dr. Manuel Vallejo Barragán. sicapacitacion.com/librospsicologia/El\%20 erotismo $\% 20 \% 20$ Georges $\% 20$ Bataille.pdf.

Barthes, Roland. El placer del texto. Siglo XXI, 1982.

Del Prado Biezma, Javier. Análisis e interpretación de la novela. Cinco modos de leer un texto narrativo. Editorial Síntesis, 2000. 
Giménez Gatto, Fabián. Erótica de la banalidad. Simulaciones, abyecciones, eyaculaciones. Fontanamara, 2011.

Gutiérrez de Velasco, Luzelena. "La violenta transformación de la violencia en Perra Brava de Orfa Alarcón”. Romance Notes, vol. 54, Special Issue, 2014, pp. 105-110.

Kristeva, Julia. Poderes del horror (fragmento), texto de circulación en el seminario Sexualidad e Identidad- dictado por Marta Iturriza y Adrián Ortiz, U.B.A. Facultad de Psicología, julio de 2010.

Ludmer, Josefina. "Literaturas posautónomas: otro estado de la escritura”. L'objet littérature, 25 dic. 2012. http:/ / oblit.hypotheses. org/277.

Mendoza, Élmer. “El arte de novelar. Orfa Alarcón”. El Universal, 8 julio 2010.

Munguía, Javier. "Perra brava, de Orfa Alarcón”. Revista de letras, 28 julio 2010. revistadeletras.net/perra-brava-de-orfa-alarcon.

Pimentel, Luz Aurora. El relato en perspectiva. Estudio de teoría narrativa. Siglo XXI/UNAM, 1998.

Rodríguez, Jaime Alejandro, editor. Hallazgos en la literatura colombiana: balance y proyección de una década de investigaciones. Editorial Pontificia Universidad Javeriana, 2010.

Torres López, Irene. "Entrevista a Orfa Alarcón". Revista La Rocka, 19 julio 2010. irenet0rres.wordpress.com/2010/07/19/entrevista-a-orfa-alarcon. 